\title{
Elderly-onset Crohn's disease remarkably responsive to ustekinumab: a case report
}

\author{
Maho Iwamoto $^{1}$ (D) Kimitoshi Kato ${ }^{2} \cdot$ Mitsuhiko Moriyama $^{1}$ \\ Accepted: 28 November 2019 / Published online: 17 December 2019 \\ (C) The Author(s) 2019
}

\begin{abstract}
Background Crohn's disease is intractable and is frequently diagnosed in younger people. No clear policies exist regarding medical treatment for seniors with this disease, and its diagnosis and treatment are often hindered by difficulties attributable to comorbidities, complex differential diagnoses, and polypharmacy. We describe an elderly-onset Crohn's disease patient showing a marked remission-maintaining effect with no adverse events after administration of ustekinumab.

Methods and results A 75-year-old patient with Crohn's disease and a history of pulmonary tuberculosis had first presented to our hospital at age 64 years and was hospitalized. Based on physical examinations, colonoscopy, and blood test results, Crohn's disease was diagnosed. The patient experienced secondary losses of responsiveness to two tumor necrosis factor (TNF)-alpha inhibitors, and after repeated hospital admissions, she was administered ustekinumab. The patient's symptoms, endoscopic findings, Crohn's Disease Activity Index, serum albumin, and physical activity levels improved markedly, and disease remission has been maintained for 2 years to date.

Conclusion Ustekinumab is an effective treatment option for elderly patients with intractable Crohn's disease when TNF-alpha inhibitors are ineffective.
\end{abstract}

Keywords Crohn's disease $\cdot$ Elderly patients $\cdot$ Ustekinumab $\cdot$ Biologic agents

\section{Introduction}

Following increases in the numbers of patients, including older people in developed countries, diagnosed with inflammatory bowel disease (IBD), there has been a rise in the numbers of patients with elderly-onset illnesses in recent years. The Crohn's disease-onset rates increased significantly from 6.84 to 22.78 per 100,000 people among adults $<60$ years of age and from 2.51 to 6.23 per 100,000 people among elderly people, i.e., those $>60$ years of age, between 1991 and 2010 [1].

Seniors may encounter more difficulties than their younger counterparts in relation to treatment, due to delays in early

Maho Iwamoto

maho_9245@yahoo.co.jp

1 Department of Internal Medicine Division of Gastroenterology and Hepatology, Nihon University School of Medicine, 30-1 Oyaguchi-Kamicho, Itabashi-ku, Tokyo 173-8610, Japan

2 Division of Research Planning and Development, Nihon University School of Medicine, 30-1 Oyaguchi-Kamicho, Itabashi-ku, Tokyo 173-8610, Japan diagnosis, age-related decreases in immunity and metabolic function, carcinogenesis, increases in comorbidities, polypharmacy, and frailty [2]. Crohn's disease is caused by genetic enteric abnormalities in immunity, and it requires treatment with biologic agents, standard glucocorticoids, and immunosuppressant agents. Since the introduction of tumor necrosis factor (TNF)-alpha inhibitors, other drugs have become available that are highly effective in patients with Crohn's disease, including ustekinumab, which is a monoclonal antibody that binds to the p40 subunit of interleukin (IL)12 and IL-23, and vedolizumab, which is an antagonist that binds to alpha-4-beta-7 integrin. Serious adverse effects (AEs), including elevated risks of infectious diseases and malignant tumors, for example, lymphomas, have been reported in patients treated with TNF-alpha inhibitors; hence, these drugs must be administered with care to elderly patients [2-4]. Although ustekinumab is considered to be a relatively safe drug, neither its effectiveness nor its safety has been determined in elderly patients with Crohn's disease [5-10].

This report describes a patient who presented with elderlyonset Crohn's disease and had experienced secondary losses of responsiveness to infliximab and adalimumab. Following 
ustekinumab treatment, she experienced no serious infectious diseases, and her nutritional status remained stable.

\section{Case presentation}

The patient is a 75-year-old woman with a history of pulmonary tuberculosis. At 64 years of age, she was hospitalized, because she had presented with a fever $\left(38.3^{\circ} \mathrm{C}\right)$, watery diarrhea ten times/day for $>2$ weeks, right lower quadrant pain, and appetite loss. At the time of her initial diagnosis, her height was $146 \mathrm{~cm}$ and weight $38 \mathrm{~kg}$. She complained of pain involving the entire abdominal area that was induced by pressure, and her white blood cell count was $11,300 / \mu \mathrm{L}$, hemoglobin concentration $9.8 \mathrm{~g} / \mathrm{dL}$, albumin level $1.4 \mathrm{~g} / \mathrm{dL}$, and C-reactive protein level $22 \mathrm{mg} / \mathrm{dL}$. The patient was diagnosed with anemia and chronic inflammation. Contrast imaging of the lower digestive tract and total colonoscopy (TCS) revealed the presence of numerous ulcers from the transverse to the ascending colon that were discontinuous and longitudinal with normal intestinal tissue between the lesions and stenoses and ulcers with a "cobblestone" appearance were identified in the ascending colon (Figs. 1a and 2b). Esophagog astroduodenoscopy showed that longitudinal ulcerated lesions were present in the lesser curvature of the stomach (Fig. 2a). No abnormalities were present in the small intestine, and she was diagnosed with Crohn's disease of the large intestine. The patient's Crohn's Disease Activity Index (CDAI) was 384, but following a fasting period and the administration of an elemental diet and 5-aminosalicylic acid, the illness showed signs of remission, and she was discharged from the hospital. The illness showed signs of recurring at age 66 years; her CDAI had increased to 299, and she had lost $5 \mathrm{~kg}$, and she was thus hospitalized again. Although rapid improvements were necessary, in consideration of the patient's age and her history of pulmonary tuberculosis, neither glucocorticoids nor immunosuppressant were administered. Working closely with a pulmonologist, isoniazid was administered prophylactically to manage the patient's chronic pulmonary tuberculosis, and infliximab $(5 \mathrm{mg} / \mathrm{kg})$ was the only other drug administered. A secondary loss of responsiveness to infliximab occurred when the patient was 70 years of age, and she was admitted again. The patient began receiving adalimumab ( $40 \mathrm{mg} /$ round) once every 2 weeks, but her symptoms recurred in association with stomatitis, and she was hospitalized for a fourth time. Given the patient's difficulties regarding ingestion, we started granulocytapheresis, but she developed septicemia from an infection contracted from a central venous catheter (CVC), which necessitated its termination. After the patient's general condition had improved, we increased the adalimumab dosage to $80 \mathrm{mg} /$ round once every 2 weeks, but the patient continued to cycle in and out of the hospital, and she was hospitalized for the seventh time when she was 73 years old. Her CDAI had deteriorated to 412 , and ustekinumab $(390 \mathrm{mg}$ ) was
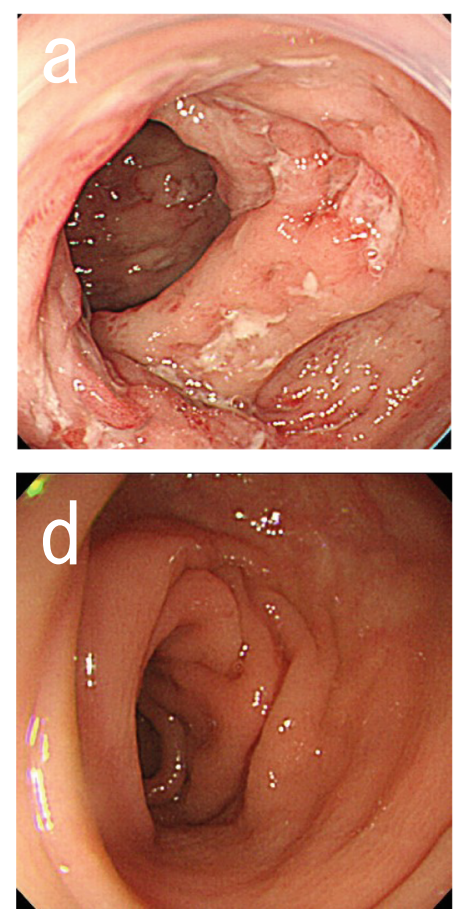

Fig. 1 Total colonoscopy findings. a Numerous irregular ulcers were observed, from the transverse to the ascending colon, during the first procedure. These ulcers were discontinuous and longitudinal with normal intestinal tissue between lesions. b 1 year later. c 3 years later,
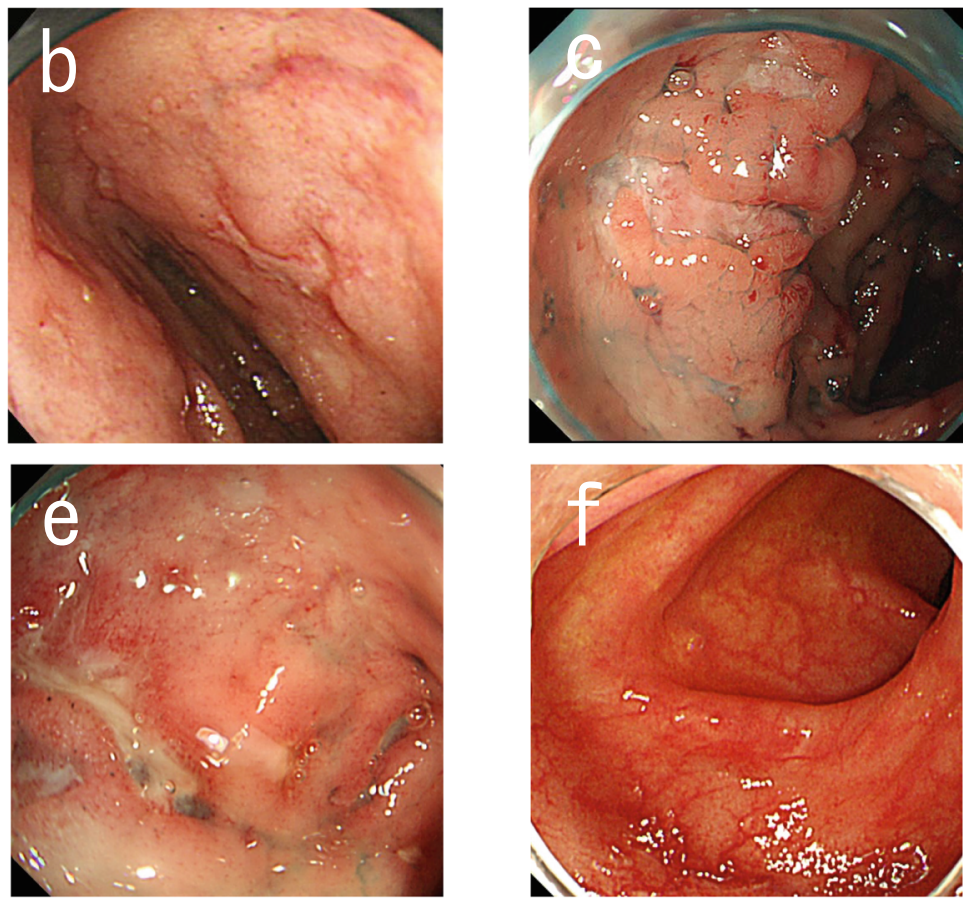

before infliximab treatment. d 6 years later, after infliximab treatment. e 8 years later, before ustekinumab treatment. f 10 years later, after ustekinumab treatment, remission was observed in the entire colon 
Fig. 2 a The upper GI endoscopic findings during the first procedure demonstrated longitudinal ulcerated lesions from the gastric cardia to the lesser curvature of the stomach (indigo carmine dispersion image). b A lower GI barium contrast radiographic study from the first procedure revealed longitudinal ulcers, a "cobblestone" appearance, and narrowing of the lumen between the transverse and ascending colon

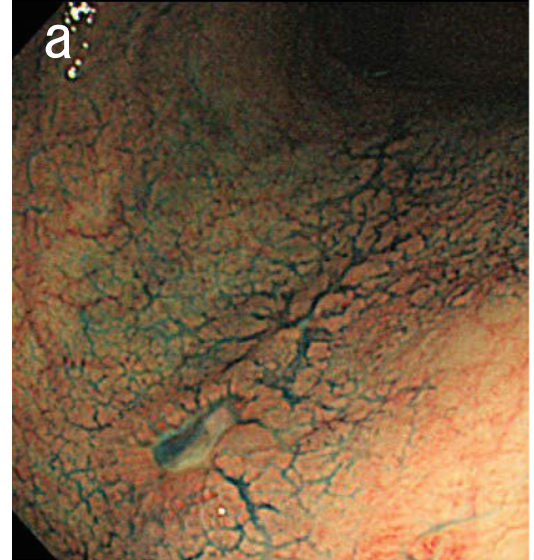

administered after 1 week; the patient's condition showed improvement, and she was able to leave the hospital. The patient's CDAI remained at 30-40 with subcutaneous injections of ustekinumab (90 mg/round) administered once every 12 weeks, and a TCS conducted 2 years later showed that the remission had been maintained within the mucosal membranes (Fig. 1f). Figure 3 illustrates the overview of this patient's 10-year clinical course, showing her CDAI, albumin levels, and treatments.

After the administration of ustekinumab, the patient's weight increased by $3 \mathrm{~kg}$, her albumin levels rose from $2.9 \mathrm{~g} / \mathrm{dL}$ to $4.7 \mathrm{~g} / \mathrm{dL}$, and her total cholesterol levels improved. Moreover, the patient's physical activity levels increased, and she currently maintains a walking rate of 10,000 steps per day.

\section{Discussion}

We have described an elderly-onset Crohn's disease patient in whom ustekinumab induced remission, which was well maintained without adverse events. The patient had been diagnosed with colonic Crohn's disease at 64 years of age, and she experienced secondary losses of responsiveness to two TNF-alpha inhibitors and suffered several recurrences. However, at age 74, she began to receive ustekinumab administration, which clearly improved the patient's symptoms and endoscopic findings, CDAI, serum albumin level, and cholesterol level, and the patient's nutritional status was maintained.

The mean age of populations in developed countries is increasing, and the number of older patients with IBD is rising. Steven et al. showed that the incidence of IBD onset among older people increased from $11.71 / 10,000$ people in 1991 to $23.66 / 10,000$ people in 2010 [1].

Medical treatment of seniors can be difficult, because physiological capabilities deteriorate with age, leading to reductions in systemic immunity and metabolic capacity, and comorbidities increase. Problems associated with frailty and sarcopenia are caused by increases in the numbers of patients in psychologically, somatically, and socially fragile states [11, 12]. Preventive treatment is recommended to address these
Fig. 3 Overview of the patient's 10-year course and management from disease onset to the present time

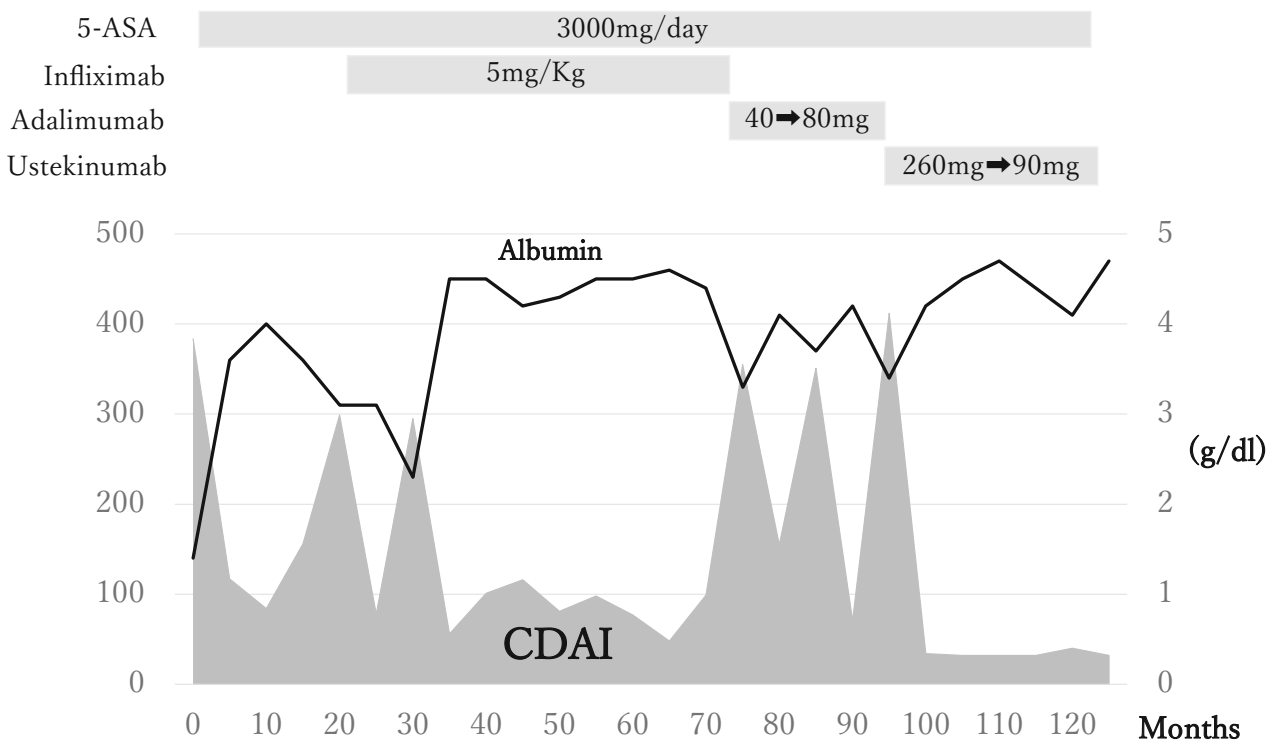


issues, and these strategies include ensuring sufficient intakes of micronutrients, macronutrients, and protein, the availability of quality foods, and that sufficient exercise is undertaken [13, 14].

Elderly patients with Crohn's disease require rapid improvements in their nutritional status to prevent frailty and sarcopenia. However, abdominal pain and diarrhea reduce food intakes and accelerate catabolism in Crohn's disease, and in patients with small intestinal Crohn's disease, particularly, this can combine with disorders associated with fat/ micronutrient digestion and absorption. During the active phase of colonic Crohn's disease, patients experience protein leakage from sores and ulcers, and their energy demands increase. The mismatch between the quantities of essential nutrients required and a patient's intake causes protein calorie malnutrition. Therefore, in addition to evaluating disease activity and mucosal healing, appropriate assessments of a patient's nutritional status become much more important. The serum albumin level indicates a patient's nutritional status, can vary according Crohn's disease status, and is thus used as an important biomarker for death in older adults $[15,16]$. The current patient had a very low albumin level $(1.4 \mathrm{~g} / \mathrm{dL})$ at disease onset when she was 64 years old, and this increased as the CDAI decreased. The albumin level decreased during recurrences and increased during remissions, reflecting a correlation with disease activity.

The inhospital mortality rate for patients $>65$ years of age with IBD is higher than that for patients with IBD who are 1964 years of age, and the adjusted odds ratio for death increases as the Charlson Comorbidity Index (CCI) score increases [17]. Following the initial onset of disease at 64 years of age, our patient was hospitalized seven times, and she experienced septicemia from a CVC infection but recovered with intensive care. Aside from pulmonary tuberculosis, our patient had no comorbid conditions, and her CCI score of 1 may have indicated her recovery.

Toruner et al. reported that immunosuppressive therapy, including corticosteroid administration, and age are risk factors associated with opportunistic infections in patients with IBD. Immunosuppressant agents increase the risk of complications arising from infections, especially when they are combined with other drugs. Brassard et al. analyzed data from $>$ 3500 patients $>66$ years of age at IBD onset in Quebec, Canada, and they showed serious infections to be associated with corticosteroid use [18, 19]. Thus, we avoided administering corticosteroids or azathioprine to our elderly patient since we felt that this would have resulted in a risk of infection. Biologic agents are essential for IBD treatment, especially for treating Crohn's disease, but they must be administered carefully to seniors. In Italy, a 10-year, multicenter, prospective study compared the effects of administering anti-TNFalpha therapy to senior and non-senior patients, comprised of 2475 patients who received infliximab and 604 given adalimumab, and the results showed higher rates of infection (11\% vs. $2.6 \%$ ), malignant neoplasms (3\% vs. $0 \%$ ), and death (10\% vs. $1 \%$ ) among the senior than non-senior patients [3]. Administering anti-TNF-alpha therapy increases the risk of malignant neoplasms and infection by 4.7-fold among seniors, i.e., patients $>65$ years of age; hence, risk-appropriate, patient-specific treatment plans that consider the advantages and disadvantages of treatment are necessary when administering biologic agents to older patients [4].

During the administration of infliximab to the current patient, prophylactic antituberculosis therapy was initially administered, and the patient was monitored for infectious diseases. She experienced a secondary loss of responsiveness to infliximab after almost 4 years, and she was thus switched to adalimumab but continued being readmitted to our hospital, due to deterioration of her condition.

Ustekinumab is a fully human monoclonal antibody, which has low immunogenicity, and reportedly shows effectiveness for Crohn's disease comparable to that of anti-TNF-alpha therapy [5]. Engel et al. analyzed real-world ustekinumab usage in 578 patients and demonstrated clinical response rates of $60 \%$, $62 \%$, and $49 \%$ at 12,24 , and 52 weeks, respectively, a 1-year endoscopic response rate of $63 \%$, serious AEs in 19 patients (3.2\%), and infections in 38 patients $(6 \%)$; none of their patients had tuberculosis [10]. Furthermore, a 5-year, long-term analysis of patients with psoriasis showed that serious drugrelated and other possible treatment-related AEs occurred in 9/774, 3/253, and 0/391 patients who received adalimumab, infliximab, and ustekinumab, respectively, indicating the latter to be safe [6]. Hence, ustekinumab has high levels of effectiveness and safety in routine clinical practice. However, its effectiveness and safety in elderly patients with Crohn's disease have not been determined.

Our patient experienced secondary losses of responsiveness to two TNF-alpha inhibitors, and she was hospitalized seven times, but after switching to ustekinumab treatment, her symptoms and endoscopic findings improved, and she went into a period of long-term, i.e., 2 years, remission. The patient's CDAI improved, serum albumin levels stabilized, nutritional status improved, and her levels of physical activity increased, which facilitated avoidance of frailty and sarcopenia. This case study shows that ustekinumab is an effective treatment option for elderly patients with intractable Crohn's disease when TNF-alpha inhibitors are ineffective.

Open Access This article is licensed under a Creative Commons Attribution 4.0 International License, which permits use, sharing, adaptation, distribution and reproduction in any medium or format, as long as you give appropriate credit to the original author(s) and the source, provide a link to the Creative Commons licence, and indicate if changes were made. The images or other third party material in this article are included in the article's Creative Commons licence, unless indicated otherwise in a credit line to the material. If material is not included in the article's 
Creative Commons licence and your intended use is not permitted by statutory regulation or exceeds the permitted use, you will need to obtain permission directly from the copyright holder. To view a copy of this licence, visit http://creativecommons.org/licenses/by/4.0/.

\section{References}

1. Jeuring SF, van den Heuvel TR, Zeegers MP, Hameeteman WH, Romberg-Camps MJ, Oostenbrug LE, Masclee AA, Jonkers DM, Pierik MJ (2016) Epidemiology and long-term outcome of inflammatory bowel disease diagnosed at elderly age-an increasing distinct entity? Inflamm Bowel Dis 22:1425-1434. https://doi.org/10. 1097/MIB.0000000000000738

2. Sturm A, Maaser C, Mendall M, Sturm A, Maaser C, Mendall M, Karagiannis D, Karatzas P, Ipenburg N, Sebastian S et al (2017) European Crohn's and colitis organisation topical review on IBD in the elderly. J Crohns Colitis 11:263-273. https://doi.org/10.1093/ ecco-jcc/jjw188

3. Cottone M, Kohn A, Daperno M, Armuzzi A, Guidi L, D'Inca R, Bossa F, Angelucci E, Biancone L, Gionchetti P, Ardizzone S, Papi C, Fries W, Danese S, Riegler G, Cappello M, Castiglione F, Annese V, Orlando A (2011) Advanced age is an independent risk factor for severe infections and mortality in patients given antitumor necrosis factor therapy for inflammatory bowel disease. Clin Gastroenterol Hepatol 9:30-35. https://doi.org/10.1016/j.cgh. 2010.09.026

4. Lobatón T, Ferrante M, Rutgeerts P, Ballet V, Van Assche G, Vermeire S (2015) Efficacy and safety of anti-TNF therapy in elderly patients with inflammatory bowel disease. Aliment Pharmacol Ther 42:441-451. https://doi.org/10.1111/apt.13294

5. Feagan BG, Sandborn WJ, Gasink C, Jacobstein D, Lang Y, Friedman JR, Blank MA, Johanns J, Gao LL, Miao Y, Adedokun OJ, Sands BE, Hanauer SB, Vermeire S, Targan S, Ghosh S, de Villiers WJ, Colombel JF, Tulassay Z, Seidler U, Salzberg BA, Desreumaux P, Lee SD, Loftus EV Jr, Dieleman LA, Katz S, Rutgeerts P, UNITI-IM-UNITI Study Group (2016) Ustekinumab as induction and maintenance therapy for Crohn's disease. N Engl J Med 375:1946-1960. https://doi.org/10.1056/NEJMoa1602773

6. Gniadecki R, Bang B, Bryld LE, Iversen L, Lasthein S, Skov L (2015) Comparison of long-term drug survival and safety of biologic agents in patients with psoriasis vulgaris. Br J Dermatol 172: 244-252. https://doi.org/10.1111/bjd.13343

7. Wheat CL, Ko CW, Clark-Snustad K, Grembowski D, Thornton TA, Devine B (2017) Inflammatory bowel disease (IBD) pharmacotherapy and the risk of serious infection: a systematic review and network meta-analysis. BMC Gastroenterol 17:52. https://doi.org/ 10.1186/s12876-017-0602-0

8. Sandborn WJ, Rutgeerts P, Gasink C, Jacobstein D, Zou B, Johanns J, Sands BE, Hanauer SB, Targan S, Ghosh S, de Villiers WJS, Colombel JF, Feagan BG (2018) Long-term efficacy and safety of ustekinumab for Crohn's disease through the second year of therapy. Aliment Pharmacol Ther 48:65-77. https://doi.org/10.1111/apt. 14794
9. Hanauer SB, Sandborn WJ, Feagan BG, Gasink C, Jacobstein D, Zou B, Johanns J, Adedokun OJ, Sands BE, Rutgeerts P et al (2019) IM-UNITI: 3 year efficacy, safety, and immunogenicity of ustekinumab treatment of Crohn's disease. J Crohns colitis Jun 3. Pii: jjz110. https://doi.org/10.1093/ecco-jcc/jjz110 [Epub ahead of print]

10. Engel T, Yung DE, Ma C, Pariente B, WIls P, Eliakim R, Ungar B, Ben-Horin S, Kopylov U (2019) Effectiveness and safety of ustekinumab for Crohn's disease; systematic review and pooled analysis of real-world evidence. Dig Liver Dis 51:1232-1240. https://doi.org/10.1016/j.dld.2019.05.002

11. Fried LP, Tangen CM, Walston J, Newman AB, Hirsch C, Gottdiener J, Seeman T, Tracy R, Kop WJ, Burke G et al (2001) Frailty in older adults: evidence for a phenotype. J Gerontol A Biol Sci Med Sci 56:M146-M156. https://doi.org/10.1093/gerona/56.3. M146

12. Cruz-Jentoft AJ, Bahat G, Bauer J, Boirie Y, Bruyère O, Cederholm T, Cooper C, Landi F, Rolland Y, Sayer AA, Schneider SM, Sieber CC, Topinkova E, Vandewoude M, Visser M, Zamboni M, Writing Group for the European Working Group on Sarcopenia in Older People 2 (EWGSOP2), and the Extended Group for EWGSOP2 (2019) Sarcopenia: revised European consensus on definition and diagnosis. Age Ageing 48:16-31. https://doi.org/10.1093/ageing/ afy 169

13. Lorenzo-López L, Maseda A, de Labra C, Regueiro-Folgueira L, Rodríguez-Villamil JL, Millán-Calenti JC (2017) Nutritional determinants of frailty in older adults: a systematic review. BMC Geriatr 17:108. https://doi.org/10.1186/s12877-017-0496-2

14. Montero-Fernández N, Serra-Rexach JA (2013) Role of exercise on sarcopenia in the elderly. Eur J Phys Rehabil Med 49:131-143

15. Corona LP, de Oliveira Duarte YA, Lebrão ML (2018) Markers of nutritional status and mortality in older adults: the role of anemia and hypoalbuminemia. Geriatr Gerontol Int 18:177-182. https:// doi.org/10.1111/ggi.13137

16. Qin G, Tu J, Liu L, Luo L, Wu J, Tao L, Zhang C, Geng X, Chen X, Ai X et al (2016) Serum albumin and C-reactive protein/albumin ratio are useful biomarkers of Crohn's disease activity. Med Sci Monit1 22:4393-4400. https://doi.org/10.12659/msm.897460

17. Ananthakrishnan AN, McGinley EL, Binion DG (2009) Inflammatory bowel disease in the elderly is associated with worse outcomes: a national study of hospitalizations. Inflamm Bowel Dis 15:182-189. https://doi.org/10.1002/ibd.20628

18. Toruner M, Loftus EV Jr, Harmsen WS, Zinsmeister AR, Orenstein R, Sandborn WJ, Colombel JF, Egan LJ (2008) Risk factors for opportunistic infections in patients with inflammatory bowel disease. Gastroenterology 134:929-936. https://doi.org/10.1053/j. gastro.2008.01.012

19. Brassard P, Bitton A, Suissa A, Sinyavskaya L, Patenaude V, Suissa S (2014) Oral corticosteroids and the risk of serious infections in patients with elderly-onset inflammatory bowel diseases. Am J Gastroenterol 109:1795-1802. https://doi.org/10.1038/ajg.2014. 313

Publisher's note Springer Nature remains neutral with regard to jurisdictional claims in published maps and institutional affiliations. 